\title{
FutureJournal
}

Profuturo: Programa de Estudos do Futuro Editor Científico: James Terence Coulter Wright Avaliação: Double Blind Review, pelo SEER/OJS Revisão: Gramática, normativa e de layout

FUTURE STUDIES RESEARCH JOURNAL:

TRENDS AND STRATEGIES

Recebido em: 12/11/2015 Aprovado em: 18/12/2015

Categoria: Relato Técnico

\section{Sistema de Gestão Integrada de Resíduos Sólidos Urbanos na Cidade Ocidental (GO)}

\author{
Evelyn Bernardo \\ Doutoranda em Administração pela Universidade Nove de Julho (UNINOVE), Brasil

\section{Heidy Rodriguez Ramos} \\ Doutora em Administração pela Universidade de São Paulo (USP), Brasil
}

\section{RESUMO}

Neste relato técnico o objetivo é apresentar a construção de um Sistema de Gestão de Resíduos Sólidos Urbanos, realizado no município de Cidade Ocidental (GO), com ênfase na implantação de uma cooperativa de catadores de materiais recicláveis. Para tanto, foi realizada uma revisão bibliográfica contendo a contextualização dos resíduos sólidos urbanos no Brasil, a gestão dos resíduos sólidos urbanos e a diretriz para a elaboração de um plano de gestão e gerenciamento de resíduos sólidos. Como fontes primárias e secundárias, foram coletadas informações do diagnóstico realizado no início da implantação do projeto, contendo os dados do município e os principais pontos de aprimoramento. Também foram registradas as informações estratégicas para implantação do projeto, como o plano de gestão dos resíduos sólidos e as ações realizadas no projeto para implantação do sistema de coleta seletiva que inclui a incorporação de tecnologias sociais e de educação ambiental, como forma de conscientização dos moradores do município. Concluiu-se que o presente relato técnico apresenta, de forma prática, o processo de implantação de um sistema de gestão integrada de resíduos sólidos urbanos, que seja econômico, eficaz e que tenha a inclusão social como premissa, especialmente das pessoas que vivem do lixo como fonte de renda. A partir do programa de coleta seletiva, foi possível maior inserção dos catadores nesse sistema, garantindo-lhes melhores condições de trabalho e renda.

PALAVRAS-CHAVE: Gestão de resíduos sólidos. Gerenciamento de resíduos sólidos. Tecnologias sociais e inclusão social. 


\section{FutureJournal}

FUTURE STUDIES RESEARCH JOURNAL:

TRENDS AND STRATEGIES

\section{System Integrated Management of Municipal Solid Waste in Cidade Ocidental (GO)}

\section{ABSTRACT}

This technical report aims to present the construction of a Waste Management System Municipal Solid, held in the city of Cidade Ocidental in Goiás with emphasis on the implementation of a cooperative of waste pickers. To that end, we conducted a literature review containing the context of urban solid waste to Brazil level, the management of municipal solid waste and the guideline for the preparation of a management plan and solid waste management. In primary and secondary sources, diagnostic information was collected performed at the beginning of project implementation, containing municipal information and main points of improvement. It also registered the strategic information for the project implementation, such as management plan for solid waste and actions of the project for implementation of the selective collection system including the incorporation of social technologies and environmental education as a form of awareness to county residents. It was concluded that this report presents a practical way of implementing a management system, enabling alternatives aiming at the implementation of an integrated management system of municipal solid waste that is economical, effective and has social inclusion as premise, especially of people living garbage as an income source. From the selective collection program could be greater integration of collectors in this system, ensuring better working conditions and income.

KEY-WORDS: Solid waste management. Solid waste. Social technologies and social inclusion management. 


\section{INTRODUÇÃO}

No mundo, a produção de resíduos sólidos vem aumentando em uma escala considerável, gerando problemas de saúde pública e poluindo o meio ambiente. No Brasil, a gestão e o manejo dos resíduos sólidos são definidos na Política Nacional de Resíduos Sólidos (PNRS), Lei n. 12.305, de 2010, regulamentada por meio do Decreto n. 7.404, de 2010, que após vinte anos de tramitação no Congresso Nacional estabeleceu um novo marco regulatório para o país (Jacobi \& Besen, 2011).

De acordo com a pesquisa Ciclosoft desenvolvida pelo Compromisso Empresarial para Reciclagem (Cempre), a maioria das iniciativas e ações de coleta seletiva é informal, com apenas 14\% dos 5.561 municípios operando programas de coleta seletiva. Desse total, $86 \%$ estão nas regiões sul e sudeste (Cempre, 2013).

Atualmente, a maioria dos centros urbanos encontra problemas para dispor o lixo no solo. A estratégia de minimização de resíduos tem se focado em evitar ao máximo os resíduos dispostos no solo a partir dos princípios de redução, reutilização e reciclagem. Com a PNRS, os munícipios estão em busca de soluções práticas para a implantação de sistemas de coleta seletiva utilizando a educação ambiental como forma de orientar a população (Bringhenti, 2004).

Os gestores do município de Cidade Ocidental (GO), após o fechamento do lixão no ano de 2008, precisando adaptar-se à lei, enfrentaram o desafio de buscar soluções para implementar um programa de coleta seletiva que incorporasse os catadores que viviam dos resíduos dispensados no lixão. Buscaram, então, resolver essa problemática por meio de consultas e estudos que possibilitassem a implentação de um sistema de coleta seletiva integrado que ofertasse capacitação aos catadores e educação ambiental para a população.

Nesse sentido, neste relato técnico o objetivo é propor, com base na revisão bibliográfica e na experiência profissional dos autores, a implantação de um sistema de gestão integrada de resíduos sólidos urbanos, com a incorporação de tecnologias sociais, gerenciamento do material reciclado e educação ambiental, como forma de conscientização 
dos moradores do município de Cidade Ocidental. O intuito foi propor alternativas para implementar um sistema que seja econômico, eficaz e que tenha a inclusão social como premissa, especialmente das pessoas que vivem ou têm o lixo como fonte de renda.

Como objetivos específicos do projeto, destacam-se:

- reativar a central de triagem de materiais recicláveis;

- estabelecer um sistema de coleta seletiva de baixo custo operacional;

- incorporar catadores informais do município ao sistema oficial de coleta seletiva;

- capacitar 20 pessoas para a formação de uma cooperativa;

- promover a participação da comunidade na gestão do sistema de coleta seletiva, por meio da educação ambiental.

\section{REFERENCIAL TEÓRICO}

O referencial teórico inclui os seguintes componentes básicos: a contextualização dos resíduos sólidos, a gestão dos resíduos sólidos urbanos (RSU), assim como as diretrizes para a elaboração de um plano de gestão e gerenciamento de resíduos sólidos.

$\mathrm{Na}$ contextualização dos resíduos sólidos, apresesentam-se informações quanto à legislação ambiental vigente e às iniciativas de coleta seletiva no Brasil. Na gestão dos RSU, apresenta-se o conceito de gerenciamento integrado dos resíduos sólidos (GIRS) e, por fim, as diretrizes para a elaboração de um plano de gestão e gerenciamento de resíduos sólidos.

\subsection{CONTEXTUALIZANDO OS RESÍDUOS SÓLIDOS URBANOS}

Segundo a norma brasileira NBR 10004 de 1987 (ABNT, 1987), os resíduos sólidos são classificados como aqueles resíduos nos estados sólidos e semissólidos que resultam de atividades da comunidade de origem industrial, doméstica, hospitalar, comercial, agrícola, de serviços e de 
varrição. Dessa forma, busca-se priorizar a redução, o reaproveitamento, o tratamento e a disposição final (Zanta \& Ferreira, 2003).

Com o passar dos anos, essa modalidade de coleta de resíduos sólidos evoluiu no país. Atualmente, 59,8\% dos 5.565 municípios brasileiros possuem iniciativas de coleta seletiva. Esse levantamento, feito para as cinco regiões do país, encontra-se apresentado na Figura 1. Apesar de os números serem expressivos, vale ressaltar que muitas dessas cidades têm apenas pontos de entrega voluntária (PEVs) ou simples formalização de parcerias com cooperativas de catadores que executam o serviço, sem um veículo de transporte (Abrelpe, 2012).

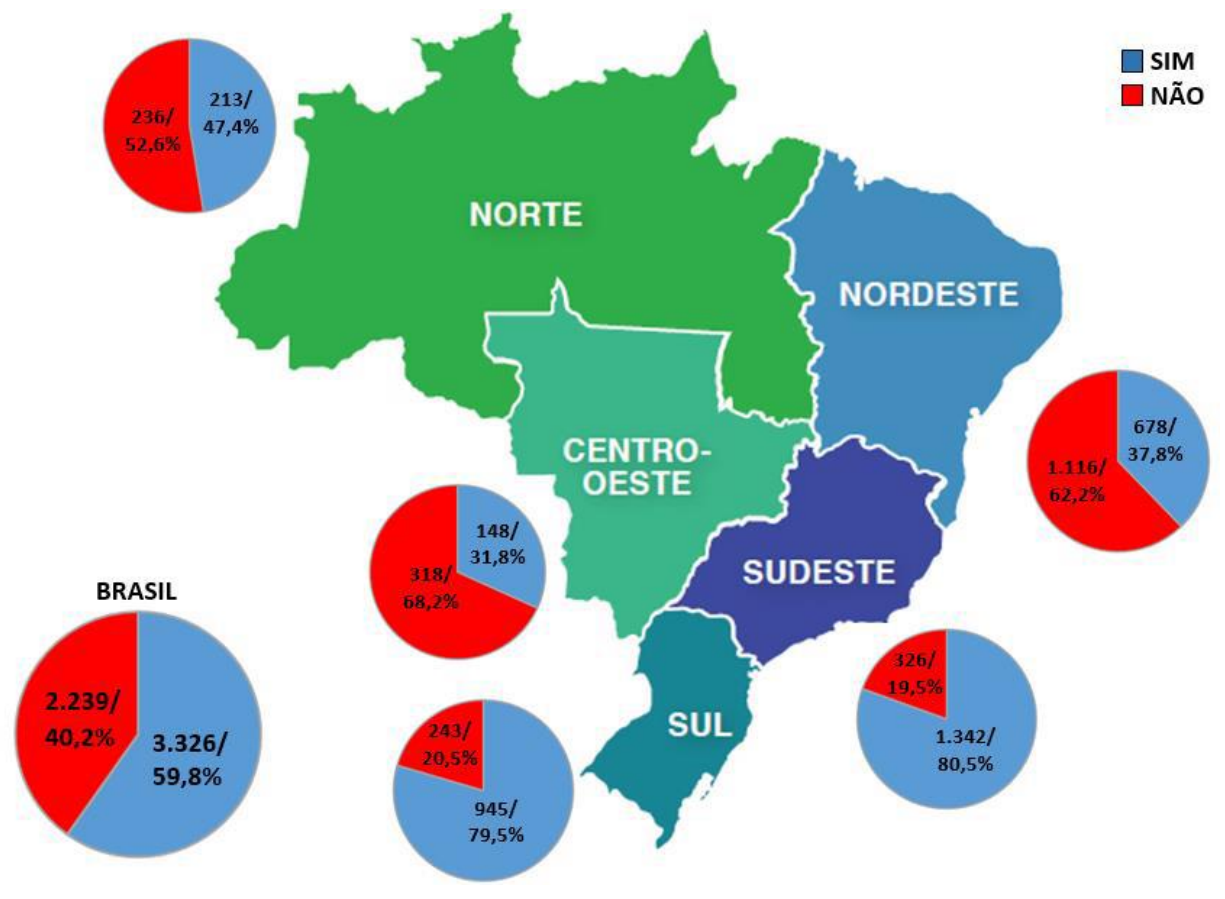

Figura 1: Municípios com iniciativas de coleta seletiva - por regiões do Brasil e total

Fonte: Abrelpe (2012)

\subsection{GESTÃO DOS RESÍDUOS SÓLIDOS URBANOS (RSU)}

Segundo Lopes (2003), entende-se como gestão dos resíduos sólidos urbanos (RSU) todas as normas e leis relacionadas a eles. Já o conceito de gerenciamento integrado dos resíduos sólidos (GIRS) engloba todas as operações que envolvem os resíduos, como coleta, tratamento, disposição final, entre outras. Dentre as atividades executadas para a gestão, o 
primeiro passo é a realização de um diagnóstico socioambiental considerando um levantamento inicial das principais potencialidades do munícipio. Após o diagnóstico, é realizado o plano participativo de gestão dos RSU apontando alternativas para seu gerenciamento e, por fim, a busca de tecnologias sociais para a inclusão social dos diferentes saberes existentes na comunidade, conforme a descrição dos pilares para a GRS na Figura 2.

Busca de tecnologias sociais para o gerenciamento dos RSU

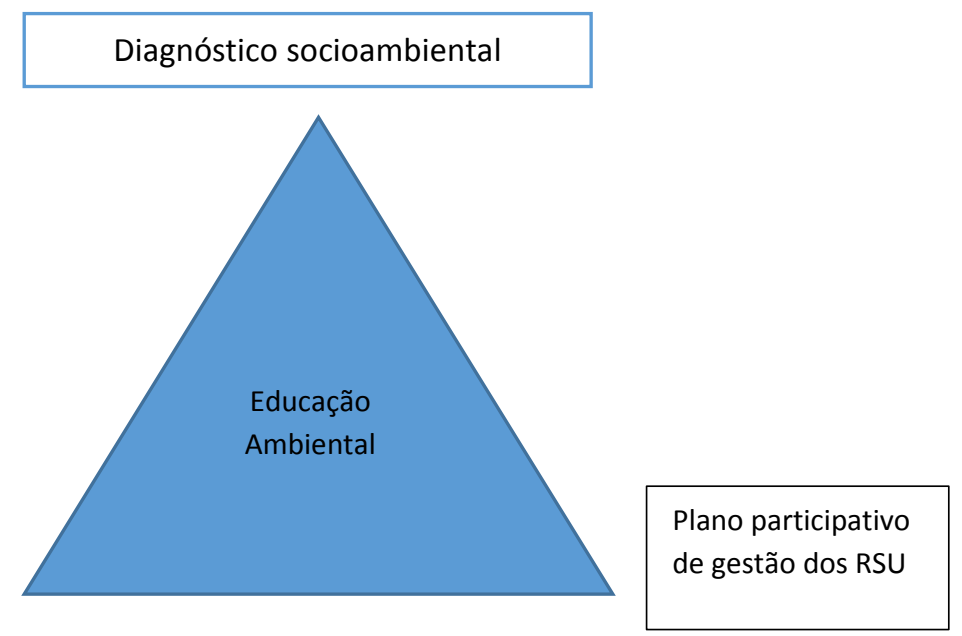

\section{Figura 2: Pilares para GRS}

Fonte: Lopes (2006)

Para Andrade (1997) e Lopes (2003), o conceito de gerenciamento surgiu na área de administração, associado às noções de planejamento e controle. Esse conceito de gerenciamento foi atrelado às medidas de preservação ambiental, economia de recursos naturais, de insumos, de energia e a minimização da poluição ambiental.

\subsection{DIRETRIZES PARA ELABORAÇÃO DE UM PLANO DE GESTÃO E GERENCIAMENTO DE RESÍDUOS SÓLIDOS}

Para a elaboração de um plano de gestão e gerenciamento de resíduos sólidos, é necessário que se inicie pela participação de um maior número de interessados, tais como representantes comunitários, governo municipal, comitê de bacias e consórcio intermunicipal e sociedade civil organizada, formado por um grupo composto em formato de rede ou fórum de discussão. Para Lopes (2003), deve ser priorizada a pesquisa para a 
obtenção de subsídios técnicos e para a formação de consórcios intermunicipais. Segundo esse autor, também é preciso incentivar os municípios a levantar dados da região referentes à geração de resíduos sólidos, qualificar os profissionais da prefeitura envolvidos e qualificar a sociedade por meio de programas de educação ambiental.

\section{CONTEXTUALIZAÇÃO DO PROJETO}

\subsection{CARACTERIZAÇÃO DO PROJETO/PROBLEMA ANALISADO}

O projeto foi desenvolvido no município da Cidade Ocidental, Estado de Goiás (Figura 3), município que compõe a Região Integrada de Desenvolvimento do Distrito Federal (RIDE) e possui cerca de 61.000 habitantes e 10.300 domicílios (IBGE, 2008).

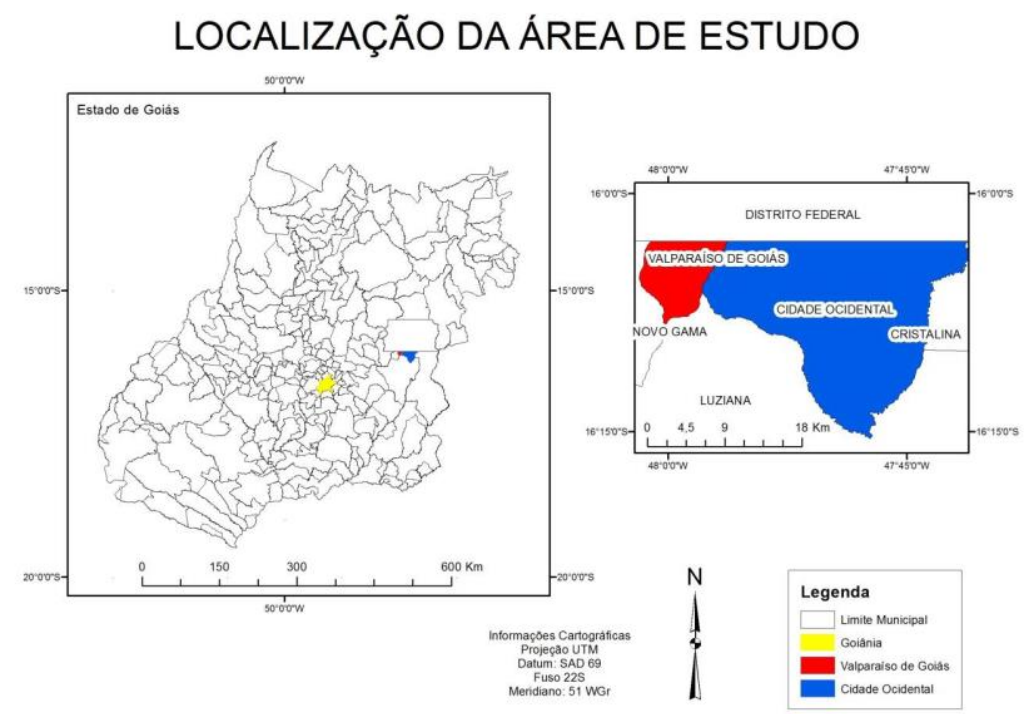

Figura 3: Localização dos municípios de Cidade Ocidental e Valparaíso de Goiás (GO)

Fonte: Adaptado de Secretaria de Indústria e Comércio (SIC, 2009)

Segundo levantamento realizado pelo município e comparado com as informações da Abrelpe (2012), no ano de 2008, em Cidade Ocidental, eram geradas em média 800 toneladas mensais de resíduos, aproximadamente 27 toneladas ao dia. Esses resíduos eram encaminhados ao aterro sanitário municipal, que, embora tivesse toda a tecnologia ambiental necessária para seu funcionamento, possuía vida útil limitada. 
Muitos dos materiais depositados no aterro não eram passíveis de reciclagem e poderiam ter sido encaminhados para outro destino mais nobre com a implantação de um sistema de coleta seletiva no município.

A coleta seletiva é a separação dos materiais de origem orgânica das embalagens feitas de plástico, papel, vidros ou metais, presentes no lixo. Ao coletar os resíduos em separado, cria-se a possibilidade de reaproveitamento dos materiais ali presentes e das embalagens, que podem retornar para a indústria como matéria-prima para novos produtos, gerando emprego e renda para as pessoas que vivem da atividade da reciclagem, além de gerar economia dos recursos naturais pela diminuição do consumo de matéria-prima virgem.

Na cidade estudada, a prefeitura municipal pretendia implantar uma central de reciclagem para triagem, armazenamento e venda dos materiais recicláveis, além de uma logística adequada de coleta e conscientização da população para a separação dos resíduos nas residências. A estimativa era reciclar 240 toneladas/mês de embalagens destinadas ao aterro que poderiam ser processadas na central de triagem.

O projeto previa também o apoio na organização de uma cooperativa de pessoas que não encontravam oportunidades de trabalho no mercado formal e que já tivessem contato com a reciclagem, aprimorando o trabalho dos catadores de forma a diminuir os índices de vulnerabilidade social no município.

\section{AÇÕES DO PROJETO PARA IMPLANTAÇÃO DO SISTEMA DE COLETA SELETIVA}

Para cumprimento dos objetivos, alguns passos foram dados. Inicialmente a elaboraçkão do diagnóstico, o planejamento do programa de coleta seletiva com as diretrizes para a reativação da central de triagem e a capacitação dos catadores de materiais reclicláveis para a formação de uma cooperativa e, por fim, a educação ambiental comunitária para promover a participação da comunidade no processo de gestão do sistema. 


\subsection{DIAGNÓSTICO SOCIOAMBIENTAL}

O primeiro passo para a implantação do projeto foi a elaboração de um diagnóstico socioambiental, que, segundo Almeida (2005), contribuiu para a tomada de decisão dos gestores públicos de municípios no sentido de equacionar problemas para implementação de um desenvolvimento em bases sustentáveis, que seja economicamente viável, socialmente justo e ecologicamente correto. O diagnóstico do município se deu no início do projeto, em 2011, conforme os dados a seguir.

O estado de Goiás tem 246 municípios, que produziam na época 643 toneladas de resíduos sólidos domiciliares ao dia (IBGE/ PNSB, 2008), o de Cidade Ocidental produzia 26,6 toneladas/dia desses resíduos, ou seja, $4,3 \%$ do total gerado no estado.

De acordo com o levantamento gravimétrico dos resíduos da cidade, realizado em maio de $2011,17 \%$ desses resíduos são compostos por plásticos, papéis, vidros e metais passíveis de reciclagem, conforme 0 Gráfico 1.

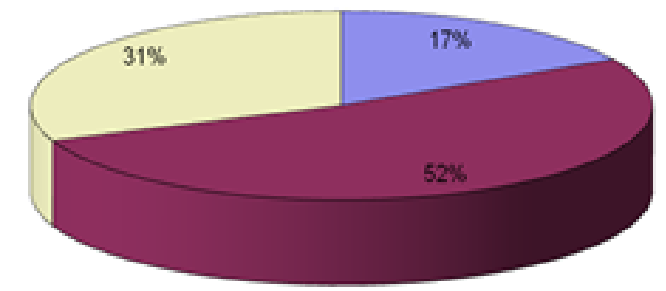

$\square$ Recicláveis $\square$ Materiais orgânicos $\square$ Rejeitos

\section{Gráfico 1: Levantamento gravimétrico dos resíduos da Cidade Ocidental}

Fonte: IBGE/ PNSB (2008)

\subsection{PLANEJAMENTO DO PROGRAMA DE COLETA SELETIVA}

A iniciativa em organizar um sistema de coleta seletiva no município partiu da prefeitura, que solicitou apoio de uma consultoria especializada para sua concretização. Desde o fechamento do antigo lixão no ano de 2008, o município buscava formas de organizar os catadores que 
trabalhavam no local e que ficaram sem seu sustento com o encerramento das atividades. Após o diagnóstico e o levantamento das demandas, foi necessário realizar um planejamento, definindo os próximos passos a serem dados, considerando os tópicos a seguir:

a) organização de uma equipe de coleta seletiva, formada por técnicos da prefeitura e vinculada ao gabinete do prefeito;

b) divisão das atividades em três frentes de trabalho: reativação da central de triagem (e formação da cooperativa com os catadores), definição da logística de coleta e educação ambiental;

c) construção de um projeto para captação de recursos e orçamento, bem como busca de parceiros financiadores;

d) reformulação do marco legal da atividade, com a aprovação da lei municipal de coleta seletiva e convênios necessários.

\subsection{CAPACITAÇÃO PARA FORMAÇÃO DA COOPERATIVA}

O cronograma de trabalho previu, após o início da construção da central de triagem, o cadastramento das pessoas que têm nos resíduos da cidade sua principal fonte de renda. Esses catadores participaram de reuniões de esclarecimento do projeto, das possibilidades da coleta seletiva e conversaram sobre os desafios e oportunidades do trabalho em cooperativa.

Os catadores cadastrados no diagnóstico que se dispuseram a participar da futura cooperativa foram capacitados para o entendimento do trabalho cooperativista e das regras de funcionamento do programa de coleta seletiva e da cooperativa, para a melhor separação dos materiais recicláveis na operação da central de triagem e para a importância de seu trabalho para o meio ambiente e a sociedade.

Com a elaboração do projeto de captação de recurso, foi possível acessar o Programa de Aceleração do Crescimento (PAC) e construir o galpão de triagem, local em que são separados os materiais provenientes da coleta e posteriormente enviados para venda por meio do caminhão da coleta (Figura 5). 

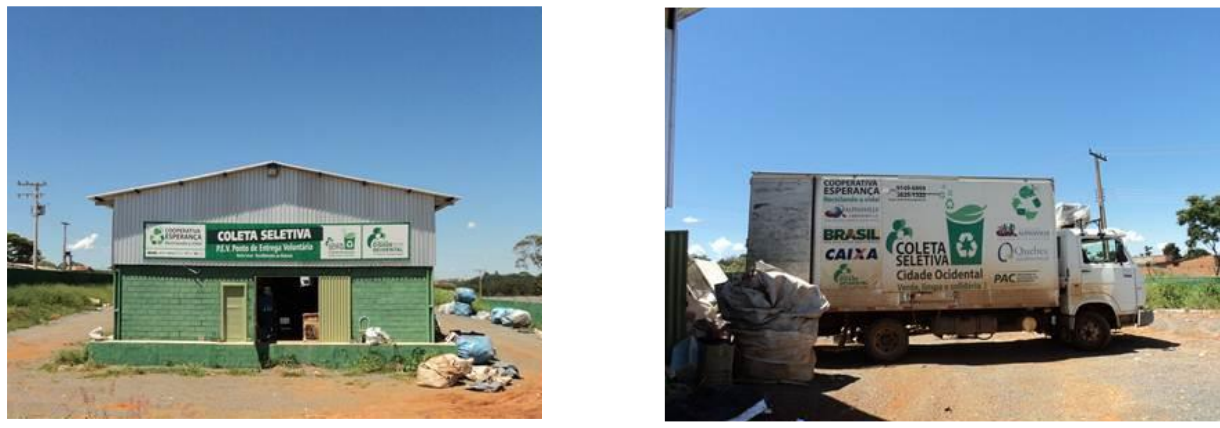

Figura 5: Central de triagem de Cidade Ocidental (GO)

(a) galpão da central de triagem. Fevereiro, 2012.

(b) Caminhão utilizado na coleta seletiva

Fonte: Acervo fotográfico da prefeitura de Cidade Ocidental

A operação no local é realizada pelos próprios cooperados (Figura 6), que, capacitados e legalizados, formam a Cooperativa Esperança de Materiais Reciclados, local de trabalho que dispõe de espaço para separação e armazenamento do material, cozinha, refeitório, banheiros e escritório.

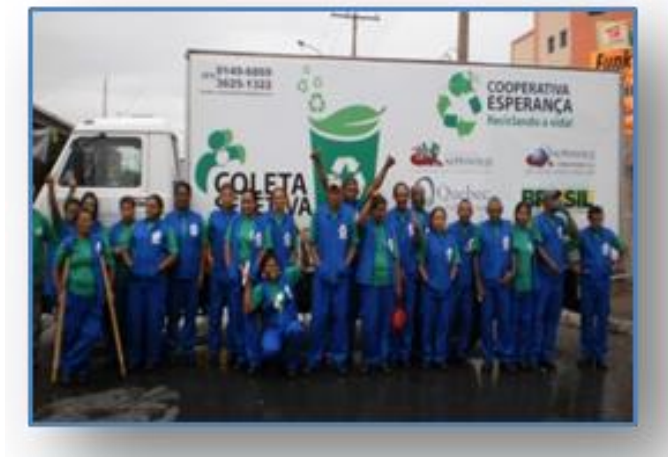

\section{Figura 6: Cooperados}

Fonte: Acervo fotográfico da prefeitura de Cidade Ocidental

Os catadores, além de agentes da coleta, desempenharam um papel fundamental na conscientização dos munícipes, tanto na implantação da coleta como na manutenção do programa, enfatizando a importância do entendimento e da corresponsabilidade em todo o processo.

A partir do traçado urbano e do mapeamento das áreas rurais de Cidade Ocidental, foi dimensionado um roteiro para a coleta dos materiais recicláveis, dividido por setores. Em cada setor, a coleta seletiva foi 
realizada de três maneiras: por meio de caminhão-gaiola, por pontos de entrega voluntária (PEVs) ou pela coleta com carrinhos adequados, conforme representado na Figura 7.

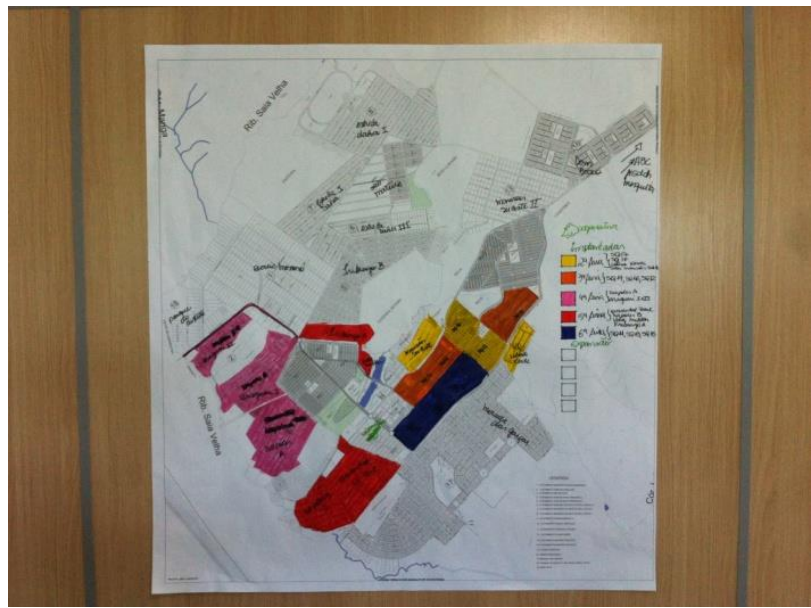

Figura 7: Organização dos roteiros de coleta seletiva

Fonte: Acervo fotográfico da prefeitura de Cidade Ocidental

\subsection{EDUCAÇÃO AMBIENTAL COMUNITÁRIA}

Para Arruda, Barbosa, Souza, Rigo \& Dal Piva (2014), a educação ambiental procura formar cidadãos cultos em matéria de ambiente, isto é, suficientemente bem informados para serem capazes de perceber seu ambiente e analisar criticamente as situações que se apresentam. Nesse sentido, todos os parceiros locais (escolas, associações, igrejas, comércio, lideranças locais e unidades de saúde) foram convidados para participar da comissão de coleta seletiva. Na Figura 8, mostra-se a capacitação dos agentes ambientais.

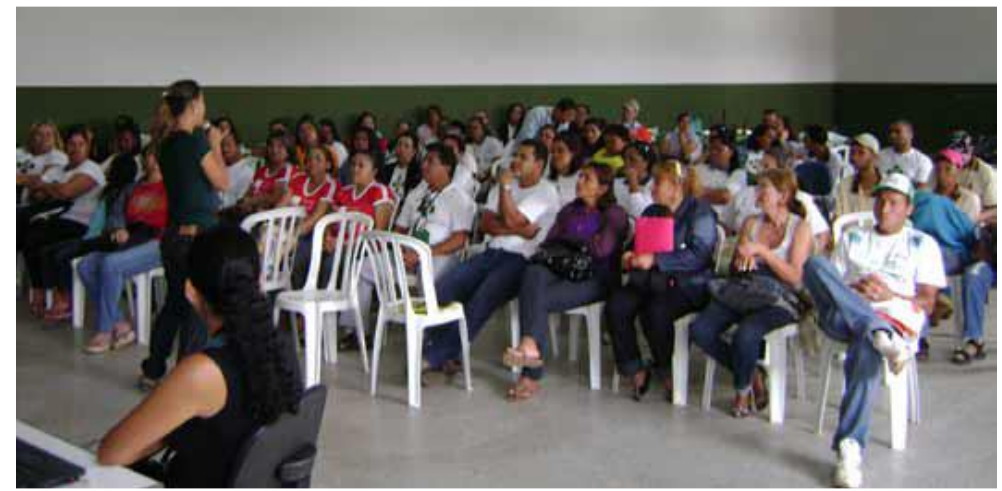

Figura 8: Capacitação dos agentes ambientais.

Fonte: Acervo fotográfico da prefeitura de Cidade Ocidental 
Além das ações capitaneadas pela cooperativa de reciclagem e pela prefeitura, foi dado suporte para que cada parceiro interessado desenvolvesse ações de educação ambiental. A implantação da coleta e a conscientização dos moradores consistiu em dividir por setores as ruas e bairros da cidade, o que garantiu uma campanha detalhada e progressiva no município. As atividades de conscientização incluíram apresentações, palestras, oficinas lúdicas e um mutirão de esclarecimento porta a porta.

Também foi elaborada campanha de comunicação, com faixas, cartazes, folhetos informativos, website, jingle da coleta, entre outros materiais. Uma ação importante, como mostrado na Figura 9, foram as distribuições dos sacos de ráfia para armazenamento dos recicláveis, atitude que aumenta em muito a adesão dos munícipes, pois somente o material é despejado no caminhão, e o morador pode reutilizar o saco.

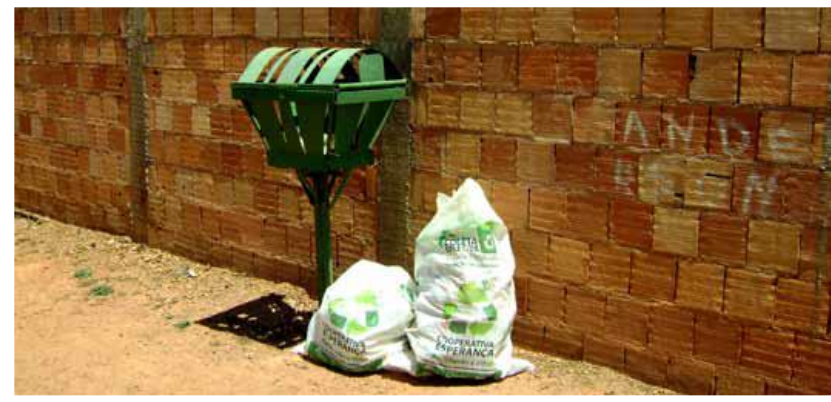

Figura 9: Distribuição de sacolas retornáveis para o armazenamento do material reciclado

Fonte: Acervo fotográfico da prefeitura de Cidade Ocidental

\section{RESULTADOS OBTIDOS E ANÁLISE}

Ao todo, o programa de coleta seletiva em Cidade Ocidental foi organizado em três anos. O objetivo do primeiro ano de trabalho, entre agosto de 2009 e agosto de 2010, foi organizar o planejamento da campanha, a captação de recursos, a construção do galpão e a legalização da cooperativa.

Com a implantação do galpão de triagem, em 2011, foi possível realizar a implantação do programa de coleta seletiva na cidade. Nesse ano, foram desenvolvidos os materiais de comunicação, as capacitações dos parceiros, os mutirões de sensibilização e, por fim, o início da coleta seletiva 
em agosto de 2011. Em um ano de execução do projeto, foi possível implantar a coleta seletiva em cinco das nove rotas previstas, atendendo os bairros de maior concentração urbana do município. Dentre os principais resultados, os que se destacaram foram:

- $50 \%$ dos munícipes atendidos pela coleta seletiva;

- 322 toneladas de materiais encaminhados à reciclagem;

- $\mathrm{R} \$ 128.882,00$ de receitas geradas;

- média de 22 postos de trabalho gerados;

- renda dos cooperados próxima ao salário mínimo.

\section{CONSIDERAÇÕES FINAIS}

A partir do diagnóstico inicial, pode-se observar grande potencial para a implantação da coleta seletiva no município e posteriormente o planejamento do programa. Dentro do planejamento, um ponto crucial para o desenvolvimento do projeto foi a formação do corpo técnico da prefeitura e a reativação da central de triagem, espaço que possibilitou a organização de um grupo de 20 catadores e implantação de um sistema de baixo custo.

Outro ponto importante foi a divisão das atividades em três frentes de trabalho: organização da central de triagem, definição da logística de coleta e educação ambiental. A capacitação, que também foi realizada para os moradores do município, teve como objetivo a sensibilização das famílias para a separação dos materiais a serem enviados para a coleta seletiva.

Com a elaboração do projeto e posterior captação de recursos, foi possível acessar o Programa de Aceleração do Crescimento (PAC) e construir o galpão de triagem. Também foi possível, com a captação de recursos, implementar um sistema de coleta seletiva de baixo custo operacional.

Para que um sistema de Gestão Integrada de Resíduos Sólidos Urbanos seja eficaz, é preciso que o sistema apresente formas práticas de implementação e que possibilite alternativas que visem à inclusão social de pessoas que têm ou usam o lixo como fonte de renda. Essa implantação obteve êxito porque foi realizada por meio da capacitação e inclusão dos catadores da região e agora segue crescendo graças a um processo de 
avaliação e monitoramento com sistema de metas de ampliação da coleta, a fim de atender o maior número de bairros até que se tenha todo município participante do sistema de coleta.

Segundo Van Bellen (2004), ferramentas de avaliação são necessárias para verificar o caminho do desenvolvimento, como sistemas de metas e critérios de desempenho mensuráveis, como no caso da coleta seletiva, que pode acompanhar o desempenho por meio do sistema de dados, que obtém informações do volume total coletado, triado, vendido, horas trabalhadas e renda média dos cooperados. 


\section{REFERÊNCIAS}

Associação Brasileira de Empresas de Limpeza Pública e Resíduos Especiais Abrelpe. (2012). Panorama dos resíduos sólidos no Brasil. Edição Especial de 10 anos. Recuperado em 23 de junho, 2015, de http://www.abrelpe.org.br/Panorama/panorama2012.pdf

Abrelpe. (2012). Panorama dos resíduos sólidos no Brasil. Edição Especial de 10 anos. Recuperado em 23 de junho, 2015, de http://www.abrelpe.org.br/Panorama/panorama2012.pdf

Almeida, L. D. (2005). Diagnóstico socioambiental e contribuições para o planejamento ambiental do município de Maracanaú-CE. Caminhos de Geografia, 11(15), 108-125.

Andrade, J. B. L de (1997). Análise do fluxo e das características físicas, químicas e microbiológicas dos resíduos de serviço de saúde: proposta de metodologia para gerenciamento em unidades hospitalares. Tese de Doutorado, Escola de Engenharia de São Carlos, Universidade de São Paulo: São Carlos, SP, Brasil.

Arruda, A. M. D., Barbosa, M. D., Souza, W. R. D., Rigo, A. S. N., \& Dal Piva, C. (2014). Conhecendo a realidade dos moradores do Parque do Sol para promover o desenvolvimento socioeconomico e ambiental. Anuário da Produção de Iniciação Científica Discente, 14(24), 91-103.

Associação Brasileira de Normas Técnicas - ABNT. (1987). NBR 10004: resíduos sólidos. Rio de Janeiro: ABNT.

Bringhenti, J. R. (2004). Coleta seletiva de resíduos sólidos urbanos: aspectos operacionais e da participação da população. Tese de Doutorado, Faculdade de Saúde Pública da Universidade de São Paulo: SP, Brasil. CEMPRE (2013). Review 2013. São Paulo: Cempre. Disponível em: <http://www.cempre. org. br>. Acesso em: Janeiro, 2016.

IBGE, (2008). Instituto Brasileiro de Geografia e Estatística. Pesquisa Nacional de Amostra por Domicílio - PNAD. IBGE: Rio de Janeiro.

IBGE/PNSB, (2008). Instituto Brasileiro de Geografia e Estatística. Pesquisa Nacional de Amostra por Domicílio - PNAD. IBGE: Rio de Janeiro. Disponível emp://www.sidra.ibge.gov.br/bda/pesquisas/pnsb/

Demográfico, I. C. (2014). Disponível em:<http://www.ibge.gov. br/home/estatistica/populacao/censo2010/default.shtm $>$.

IBGE (2008). Instituto Brasileiro de Geografia e Estatística. Pesquisa Nacional de Amostra por Domicílio - PNAD. IBGE: Rio de Janeiro. 
Jacobi, P. R., \& Besen, G. R. (2011). Gestão de resíduos sólidos em São Paulo: desafios da sustentabilidade. Estudos Avançados, 25(71), 135158. Recuperado em 20 de novembro, 2014, de http://www.scielo.br/scielo.php?script=sci arttext\&pid=S0103-

Lopes, A. A. (2003). Estudo da gestão e do gerenciamento integrado dos resíduos sólidos urbanos no município de São Carlos (SP). Dissertação de Mestrado, Escola de Engenharia de São Carlos, Universidade de São Paulo: São Carlos, SP, Brasil.

Lopes, L. (2006). Gestão e gerenciamento integrados dos resíduos sólidos urbanos: alternativas para pequenos municípios. Dissertação de Mestrado, Faculdade de Filosofia, Letras e Ciências Humanas da Universidade de São Paulo: SP, Brasil.

Ministério do Meio Ambiente. (2014). Governança ambiental, geoprocessamento. Fonte: Ministério do Meio Ambiente: http://www.mma.gov.br/governanca-ambiental/geoprocessamento

SIEG (2009). Limites municípais da base cartográfica planialtimétrica de Goiás. SIEG-Sistema Estadual de Geoinformação - Goiás. Recuperado em 3 de junho, 2015, de http://www2.sieg.go.gov.br/pagina/ver/11587/mapas-interativos.

Van Bellen, H. M. (2004). Desenvolvimento sustentável: uma descrição das principais ferramentas de avaliação. Ambiente \& Sociedade, 7(1), 67-88.

Zanta, V. M., \& Ferreira, C. F. A. (2003). Gerenciamento integrado de resíduos sólidos urbanos. In A. B. de Castilho Júnior (Coordenador), Resíduos sólidos urbanos: aterro sustentável para municípios de pequeno porte. São Carlos, SP: Rima Artes e Textos. 